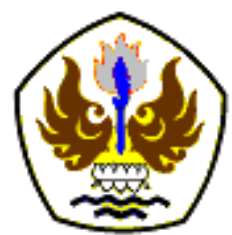

INFOMATEK

Volume 19 Nomor 1 Juni 2017

\title{
ANALISIS PEMETAAN BUDAYA ORGANISASI MENGGUNAKAN ORGANIZATION CULTURE ASESSEMENT INSTRUMENT (OCAI) (STUDI KASUS AUTO 2000 CABANG SETIABUDHI BANDUNG)
}

\author{
Rizki Wahyuniardi ${ }^{*}$, Apep Rahmat, Ahmad Faisal Nurcholis \\ Program Studi Teknik Industri \\ Fakultas Teknik - Universitas Pasundan - Bandung
}

\begin{abstract}
Abstrak: AUTO 2000 Cabang Setiabudhi Bandung merupakan jaringan jasa penjualan, perawatan, perbaikan dan penyediaan produk Toyota. Perusahaan ini merupakan dealer Toyota yang sukses di pasar nasional. Kesuksesan ini tidak luput dari persaingan yang ketat. Untuk memenangkan persaingan, diperlukan kondisi perusahaan yang adaptif dengan membangun dan menerapkan budaya organisasi yang sesuai. Penelitian ini bertujuan untuk mengetahui budaya organisasi, hasil pemetaan dan analisis rekomendasi di masa datang dengan menggunakan metode Organization Culture Asessement Instrument (OCAI). Metode ini digunakan untuk mengetahui budaya yang dirasakan saat ini dan yang diharapkan kedepannya. Tipe budaya dalam OCAI dibagi 4 yaitu: Clan, Adhocrachy, Market dan Hierarchy. Berdasarkan hasil penelitian diketahui bahwa budaya perusahaan saat ini adalah budaya market dan harapan pegawai terhadap budaya perusahaan di masa datang adalah market, clan dan hierarchy. Hal ini bisa dipengaruhi deskripsi pekerjaanya sehingga terfokus terhadap pekerjaan yang diberikan dan tidak melihat keadaan perusahaan secara umum. Dengan demikian dapat disimpulkan perlunya penyesuaian budaya organisasi menggunakan OCAI dengan visi, misi, serta nilai-nilai yang ada di perusahaan.
\end{abstract}

Kata kunci: Budaya Organisasi, AUTO 2000, Organization Culture Asessement Instrument (OCAI).

\section{PENDAHULUAN}

\subsection{Latar Belakang}

Penelitian ini didasari oleh penelitian yang telah dilakukan oleh Quinn [1]. Dalam bukunya dijelaskan tentang cara menganalisis budaya organisasi menggunakan instrumen Organization Culture Asessement Instrument (OCAI). Penelitian tentang pemetaan budaya organisasi dengan menggunakan metode

*) rizki.wahyuniardi@unpas.ac.id
OCAI pernah dilakukan oleh beberapa peneliti seperti Umartias [2], Hitka [3] dan Cendana [4]. Ketiga penelitian menghasilkan kesimpulan bahwa setiap individu dalam organisasi memiliki pendapat tersendiri mengenai budaya organisasi saat ini dan harapan di masa datang.

AUTO 2000 Cabang Setiabudi Bandung
merupakan jaringan jasa penjualan,
perawatan, perbaikan dan penyediaan suku


cadang Toyota. Perusahaan ini merupakan dealer Toyota yang sudah sukses di pasar nasional khususnya di wilayah regional Bandung. Kesuksesan ini hasil kerja keras pegawainya untuk menghadapi persaingan yang ketat. Dalam menghadapi persaingan yang ketat tersebut membuat perusahaan menyadari pentingnya memiliki kondisi perusahaan yang adaptif, sehingga dapat memberikan dorongan pada Sumber Daya Manusia (SDM) yang bekerja untuk mencapai misi dan tujuan perusahaan. Kondisi perusahaan akan menjadi adaptif ketika budaya organisasi yang diterapkan di perusahaan berkontribusi terhadap kinerja karyawan (Suryani [5]).

Penelitian ini bertujuan untuk mengetahui profil budaya organisasi yang dirasakan saat ini dan yang diharapkan oleh kayawan di AUTO 2000 Cabang Setiabudi Bandung, mengetahui klasifikasi pemetaan budaya serta memberikan analisis dan rekomendasi dari hasil pemetaan budaya yang telah dilakukan. Dari penelitian ini akan diberikan gambaran terhadap budaya organisasi yang sebaiknya dijalankan di perusahaan.

\section{METODOLOGI}

\subsection{Responden}

Responden yang digunakan dalam penelitian ini berjumlah 16 orang. Responden merupakan pimpinan dari setiap bagian yang ada di perusahaan. Sesuai dengan Efendi [6], bahwa yang memiliki pengaruh terhadap komitmen organisasi karyawan adalah kecerdasan emosional pemimpin, sehingga bawahannya dapat mengikuti dimensi yang dimiliki pemimpinnya. Pimpinan yang dimaksud dalam penelitian ini dan jumlah responden yang dijadikan bahan penelitian sesuai dengan struktur organisasi di perusahaan diperlihatkan pada Tabel 1.

Tabel 1

Jabatan Responden dan jumlahnya

\begin{tabular}{|c|c|c|c|c|c|}
\hline No & Jabatan & Jumlah & No & Jabatan & Jumlah \\
\hline 1 & $\begin{array}{l}\text { Kepala } \\
\text { Cabang }\end{array}$ & 1 & 6 & $\begin{array}{l}\text { Kepala } \\
\text { Security }\end{array}$ & 1 \\
\hline 2 & Supervisor & 2 & 7 & $\begin{array}{l}\text { Kepala } \\
\text { Service }\end{array}$ & 2 \\
\hline 3 & $\begin{array}{l}\text { Kepala } \\
\text { Administration } \\
\text { Department } \\
\text { Head }\end{array}$ & 1 & 8 & $\begin{array}{l}\text { Ketua Tim } \\
\text { Sales } \\
\text { Force }\end{array}$ & 5 \\
\hline 4 & $\begin{array}{l}\text { Kepala } \\
\text { Bengkel }\end{array}$ & 1 & 9 & $\begin{array}{l}\text { Kepala } \\
\text { Onderdil }\end{array}$ & 1 \\
\hline 5 & $\begin{array}{l}\text { Kepala } \\
\text { Customer } \\
\text { Relation Care }\end{array}$ & 1 & 10 & $\begin{array}{l}\text { Kepala } \\
\text { Booking } \\
\text { Service }\end{array}$ & 1 \\
\hline
\end{tabular}

\subsection{Organization Culture Asessement Instrument (OCAI)}

Alat dalam mengumpulkan informasi penelitian menggunakan kuesioner untuk mengetahui jawaban dari setiap responden, dengan menggunakan kuesioner OCAl yang terdiri dari 6 kriteria yaitu karakteristik dominan, kepemimpinan organisasi, pengelolaan karyawan, perekat organisasi, penekanan strategis dan kriteria keberhasilan. Langkah- 
langkah yang dilakukan untuk melakukan penelitian ini dijelaskan sebagai berikut:

1. Responden mengisi kuesioner OCAI sesuai dengan persepsi saat ini $\left(x_{i . n}\right)$ dan harapan $\left(y_{i . . n}\right)$ untuk 6 dimensi yang ada. Angka yang diberikan adalah $10-100$, dimana 10 adalah terkecil.

2. Melakukan transformasi data untuk 6 dimensi di setiap pertanyaan A - D dengan rumus :

$x_{i}^{\prime}=x_{i} / S x * 100 \% \ldots(1)$

$y_{i}^{\prime}=y_{i} / S y^{*} 100 \% \ldots(2)$

dimana :

$\mathrm{x}_{i}=\mathrm{y}_{i}=$ jawaban responden awal

$\mathrm{x}^{\prime}{ }_{i}=\mathrm{y}_{i}^{\prime}=$ jawaban responden hasil transformasi

3. Menjumlahkan $x_{i}^{\prime}$ dan $y_{i}^{\prime}$ untuk masingmasing pertanyaan $A\left(x_{i}^{\prime} A\right.$ dan $\left.y_{i}^{\prime} A\right)$ hingga $\mathrm{D}\left(x_{i}^{\prime} \mathrm{D}\right.$ dan $\left.y_{i}^{\prime} \mathrm{D}\right)$ untuk 6 indikator.

4. Memplot nilai rata-rata $x_{i}^{\prime}$ dan rata-rata $y_{i}{ }_{i}$ untuk A hingga $D$ di Competing Value Framerwork (CVF) dengan ketentuan sebagai berikut:

Tipe A = Tipe Budaya Clan

Tipe B = Tipe Budaya Adhocracy

Tipe $\mathrm{C}=$ Tipe Budaya Market

Tipe D = Tipe Budaya Hierarchy

5. Tentukan nilai maksimum nilai rata-rata $x^{\prime}{ }_{i}$ dan rata-rata $y_{i}^{\prime}$ untuk keputusan tipe budaya yang kuat.

Contoh penggambaran CVF diperlihatkan pada Gambar 1.

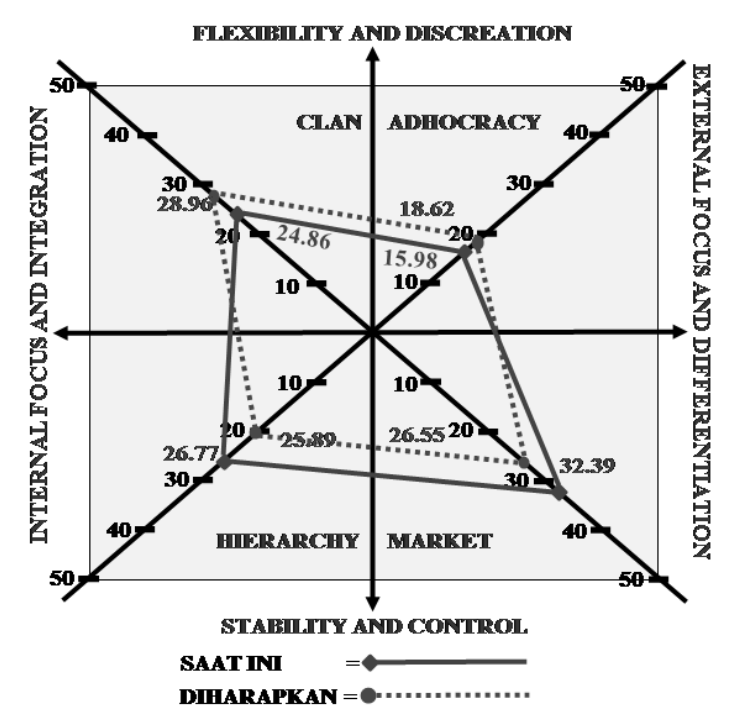

Gambar 1.

CFV

\section{ANALISIS DAN PEMBAHASAN}

\subsection{Pengolahan Data}

Hasil pengolahan data untuk salah satu responden (Kepala Cabang) diperlihatkan pada Tabel 2.

\section{Tabel 2}

Nilai rata-rata

\begin{tabular}{|c|c|c|c|c|}
\hline Tipe & $\begin{array}{c}\text { Saat Ini } \\
\boldsymbol{x}_{\boldsymbol{i}}\end{array}$ & $\begin{array}{c}\text { Harapan } \\
\boldsymbol{y}_{\boldsymbol{i}}\end{array}$ & $\begin{array}{c}\text { Saat Ini } \\
\boldsymbol{x}_{\boldsymbol{i}}\end{array}$ & $\begin{array}{c}\text { Harapan } \\
\boldsymbol{y}^{\prime} \boldsymbol{i}\end{array}$ \\
\hline A & 49,17 & 54,17 & 17,68 & 17,68 \\
\hline B & 60,00 & 75,00 & 20,74 & 23,79 \\
\hline C & 95,00 & 98,33 & 33,08 & 31,29 \\
\hline D & 83,33 & 87,50 & 29,10 & 27,84 \\
\hline
\end{tabular}

Dari Tabel 2 dapat dilihat bahwa tipe budaya kuat yang dirasakan maupun diharapkan Kepala Cabang adalah tipe budaya market. Tipe budaya market memfokuskan pada hubungan (transaction) khususnya pada institusi diluar organisasi, seperti supplier, 
customer, kontraktor, pemberi lisensi, dan pemerintah. Pengawasan internal dalam tipe budaya ini tergantung pada mekanisme ekonomi pasar, khususnya pada nilai tukar uang. Nilai inti pada budaya ini adalah kompetisi (competitiveness) dan produktivitas (productivity). Penggambaran CFV untuk memperlihatkan tipe budaya yang dianut oleh Kepala Cabang diperlihatkan pada Gambar 2.

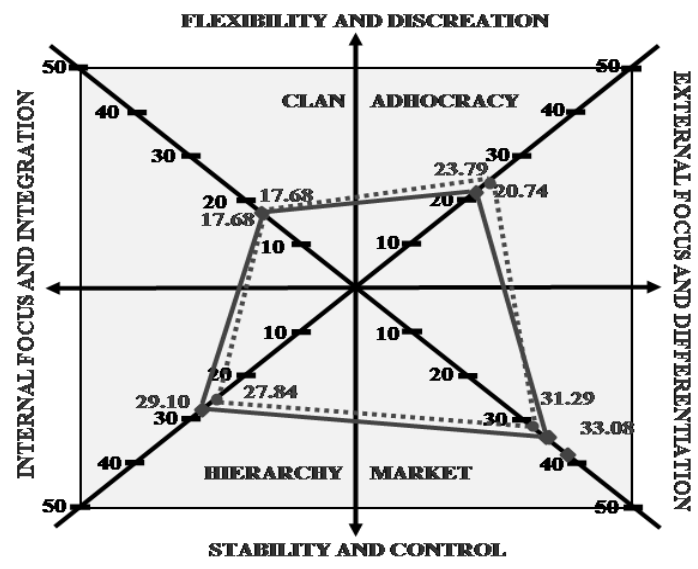

Gambar 2.

CFV untuk Kepala Cabang

Untuk rekapitulasi nilai rata-rata seluruh responden untuk $x_{i}^{\prime}$ dan $y_{i}^{\prime}$ dapat dilihat pada Tabel 3 dan Tabel 4.

Tabel 3

Nilai rata-rata untuk tipe budaya saat ini

\begin{tabular}{|l|c|c|c|c|}
\hline \multicolumn{1}{|c|}{ Jabatan } & A & B & C & D \\
\hline Kepala Cabang & 17,08 & 20,74 & 33,08 & 29,10 \\
\hline Supervisor 1 & 21,14 & 21,27 & 33,92 & 23,67 \\
\hline Supervisor 2 & 21,95 & 19,55 & 30,12 & 28,38 \\
\hline $\begin{array}{l}\text { Kepala Adm. } \\
\text { Department Head }\end{array}$ & 23,15 & 22,38 & 28,47 & 26,00 \\
\hline Kepala Bengkel & 23,69 & 19,01 & 29,10 & 28,20 \\
\hline $\begin{array}{l}\text { Kepala Customer } \\
\text { Relation Care }\end{array}$ & 24,11 & 19,75 & 28,20 & 27,94 \\
\hline Kepala Security & 27,23 & 20,70 & 23,31 & 28,76 \\
\hline
\end{tabular}

\begin{tabular}{|l|c|c|c|c|}
\hline \multicolumn{1}{|c|}{ Jabatan } & A & B & C & D \\
\hline Ketim Sales 1 & 24,65 & 22,21 & 27,93 & 25,22 \\
\hline Ketim Sales 2 & 21,18 & 24,66 & 30,37 & 23,79 \\
\hline Ketim Sales 3 & 22,28 & 23,11 & 30,40 & 24,22 \\
\hline Ketim Sales 4 & 21,97 & 24,16 & 28,45 & 25,42 \\
\hline Ketim Sales 5 & 23,06 & 23,33 & 28,74 & 24,87 \\
\hline Kepala Service 1 & 21,89 & 21,57 & 28,45 & 28,09 \\
\hline Kepala Service 2 & 24,09 & 23,99 & 27,54 & 24,39 \\
\hline $\begin{array}{l}\text { Kepala Booking } \\
\text { Service }\end{array}$ & 22,92 & 21,78 & 30,63 & 24,67 \\
\hline Kepala Onderdil & 23,43 & 22,78 & 28,18 & 25,61 \\
\hline Total & 363,82 & 350,98 & 466,87 & 418,33 \\
\hline Budaya Organisasi & 22,74 & 21,94 & 29,18 & 26,15 \\
\hline
\end{tabular}

Tabel 4

Nilai rata-rata untuk tipe budaya harapan

\begin{tabular}{|l|c|c|c|c|}
\hline \multicolumn{1}{|c|}{ Jabatan } & A & B & C & D \\
\hline Kepala Cabang & 17,08 & 23,79 & 31,29 & 27,84 \\
\hline Supervisor 1 & 23,46 & 21,00 & 29,78 & 25,76 \\
\hline Supervisor 2 & 24,29 & 20,72 & 28,25 & 26,73 \\
\hline $\begin{array}{l}\text { Kepala Adm. } \\
\text { Department Head }\end{array}$ & 25,29 & 24,60 & 26,26 & 23,84 \\
\hline Kepala Bengkel & 27,10 & 23,48 & 24,98 & 24,44 \\
\hline $\begin{array}{l}\text { Kepala Customer } \\
\text { Relation Care }\end{array}$ & 27,63 & 21,20 & 25,67 & 25,50 \\
\hline Kepala Security & 27,56 & 22,36 & 23,89 & 26,19 \\
\hline Ketim Sales 1 & 26,72 & 22,87 & 26,95 & 23,46 \\
\hline Ketim Sales 2 & 26,47 & 23,84 & 26,75 & 22,93 \\
\hline Ketim Sales 3 & 24,61 & 22,25 & 27,68 & 25,46 \\
\hline Ketim Sales 4 & 25,69 & 24,09 & 25,69 & 24,53 \\
\hline Ketim Sales 5 & 25,35 & 23,48 & 25,12 & 26,05 \\
\hline Kepala Service 1 & 27,33 & 22,64 & 24,17 & 25,86 \\
\hline Kepala Service 2 & 28,56 & 23,38 & 23,53 & 24,52 \\
\hline $\begin{array}{l}\text { Kepala Booking } \\
\text { Service }\end{array}$ & 25,12 & 23,48 & 26,79 & 24,61 \\
\hline Kepala Onderdil & 27,29 & 24,17 & 23,95 & 24,58 \\
\hline Total & 409,56 & 367,37 & 420,76 & 402,31 \\
\hline Budaya Organisasi & 25,60 & 22,96 & 26,30 & 25,14 \\
\hline
\end{tabular}

Dari Tabel 3 dan Tabel 4 dapat dilihat bahwa terjadi perubahan harapan penerapan budaya organisasi di perusahaan. Kepala bengkel misalnya, berharap agar budaya organisasi di perusahaan sudah mengarah kepada budaya clan. Budaya clan memiliki persamaan dengan budaya hirarki, terutama dalam hal fokus pada proses internal dan integrasi. Perbedaannya, budaya clan menekankan 
pada fleksibilitas dan kebijaksanaan daripada stabilitas dan integrasi [1]. Kecepatan dalam pengambilan keputusan menjadi faktor penting yang perlu dipertimbangankan oleh perusahaan. Meskipun demikian, secara ratarata nilai budaya organisasi yang kuat adalah budaya market, sesuai dengan Gambar 3 .

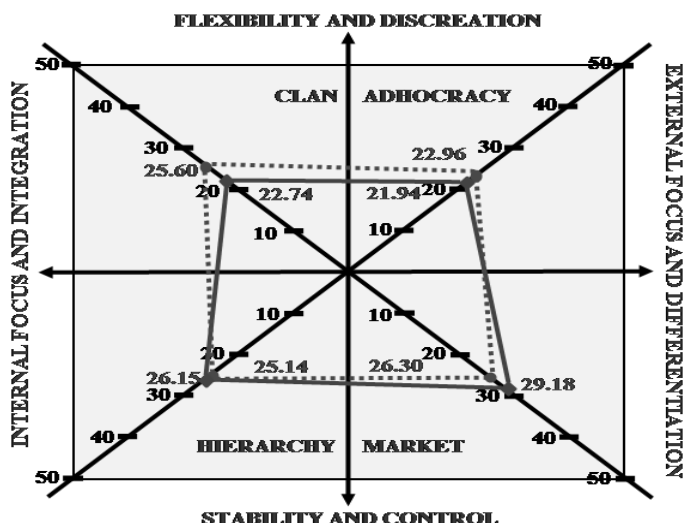

Gambar 3.

CFV untuk Budaya Organisasi rata-rata

\subsection{Analisis dan Pembahasan}

Berdasarkan hasil dari pengolahan data pada Tabel 3 dan Tabel 4 serta hasil pemetaanya pada Gambar 3, yang menunjukan bahwa budaya yang dirasakan saat ini oleh perusahaan yaitu budaya market, sedangkan yang diharapkan untuk kedepannya yaitu budaya market, clan dan hierarchy. Hal ini berarti perusahaan harus lebih fokus namun fleksibel terhadap stabilitas dan kontrol. Dengan diketahuinya bahwa pegawai menyatakan budaya market, clan dan hieerarchy maka berarti perusahaan tetap fokus pada hubungan-hubungan dan transaksi-transaksi dengan pemasok/ pelanggan namun juga tetap fleksibel.
Pengelolaan sumber daya manusia di perusahaan berorientasi pada hasil dan kompetisi. Pemimpin dalam perusahaan ini merupakan orang yang menuntut, pendorong, dan produktif. Penekanan pada kemenangan menjadi tujuan yang mempersatukan karyawan di perusahaan. Fokus perhatian pada sukses dan reputasi. Suksesnya perusahaan diartikan dengan penguasaan pangsa pasar dan penetrasi, mementingkan harga yang kompetitif dan kepemimpinan pasar. Nilai inti dari perusahaan ini berarti kompetisi dan produktivitas.

Perusahaan juga tetap mengharapkan mempertahankan budaya yang dirasakan saat ini, ini menunjukan bahwa pegawai secara keseluruhan tidak ingin merubah budaya yang sedang berjalan saat ini. Namun tetap sesuai dengan tugas masing-masing bagiannya. Jika dikaitkan dengan nilai-nilai perusahaan ataupun visi misi perusahaan, memang sudah jelas bahwa budaya market, clan dan hierarchy ini sangat cocok terhadap perusahaan. Secara garis besar, visi dan misi perusahaan yaitu menjadi penguasa pangsa pasar di seluruh Indonesia dalam bidang penjualan mobil Toyota dan menjaga kualitas pelayanan terhadap pelanggan. Nilai-nilai yang diterapkan di perusahaan juga sangat merujuk terhadap kepuasan pelanggan. Dengan kata lain budaya perusahaan ini bisa menjadi tolak ukur untuk seluruh karyawan di AUTO 2000 Cabang Setiabudi Bandung, karena dengan adanya kesepahaman budaya dengan visi dan misi ataupun nilai-nilai 
perusahaan akan membuat perusahaan mencapai visi dan misinya.

\section{KESIMPULAN}

Beberapa kesimpulan yang dapat diambil dari penelitian ini adalah:

1. Budaya organisasi kuat yang dianut saat ini oleh sebagian besar pimpinan adalah budaya market. Hanya satu pimpinan yaitu Kepala Security yang menyatakan budaya hierarchy.

2. Budaya organisasi yang diharapkan oleh di masa datang oleh Kepala Cabang, Supervisor, Kepala Adm. Department Head, Ketua Sales 1 - 4 dan Kepala Booking Service adalah budaya market, sedangkan Kepala Bengkel, Kepala Customer Relation Care, Kepala Security, Kepala Service Kepala Service dan Kepala Onderdil mengharapkan budaya clan. Hanya satu pimpinan yaitu Ketua Sales 5 yang menyatakan budaya hierarchy.

3. Perlu dilakukan sosialisasi perusahaan kepada jajaran pimpinan dalam struktur organisasi untuk tetap fokus pada terhadap stabilitas dan kontrol. Perubahan tipe budaya yang diharapkan dapat diterapkan di masa mendatang, menunjukkan perlu adanya penyesuaian fleksibilitas dan kebijakan perusahaan untuk tetap dapat mencapai visi dan misinya.

\section{DAFTAR PUSTAKA}

[1] Quinn, Robert E and Kim S, Cameron, 2006, Diagnosing and Changing
Organizational Culture "Based on the Competing Values Framework", Revised Edition, Jossey - Bass, United States of America.

[2] Umartias, Muhammad, 2014, Pemetaan Budaya Organisasi Menggunakan Organizational Culture Assessment Instrument (OCAI) Pada PT Kereta Api Indonesia Daerah Operasional 4 Semarang, Diponegoro Journal Of Management, Vol. 6, No. 2, hal. 1 - 15.

[3] Hitka, Milos, dkk., 2015, Corporate Culture as a Tool for Competitiveness Improvement, Procedia Economics and Finance, Vol. 34, pp. 27 - 34

[4] Cendana, Syafiq Dinka Muhammad, 2016, Analisis Pemetaan Budaya Organisasi Menggunakan Organizational Culture Assessment Instrument (OCAI) Pada PT. Angkasa Pura I Bandara Internasional Ahmad Yani Semarang, Diponegoro Journal Of Management, Vol. 5, No. 3, hal.1-14

[5] Suryani, Dewi, Budiono, 2016, Pengaruh Budaya Organisasi Terhadap Kinerja Karyawan melalui Komitmen Organisasi sebagai variabel Intervening pada PT. Kertas Rajasa Raya, Jurnal Riset Ekonomi dan Manajemen, Vol. 16, No. 1, hal. 29 -43

[6] Efendi, Verisa A., Eddy Madiono Sutanto, 2013, Pengaruh Faktor-Faktor Kecerdasan Emosional Pemimpin terhadap Komitmen Organisasional Karyawan di Universitas Kristen Petra, AGODA, Vol. 1, No. 1 